\title{
Determination of the quality of stripe-marked and cracked eggs during storage
}

\author{
Yu Chi Liu', Ter Hsin Chen ${ }^{2}$, Ying Chen $\mathrm{Wu}^{2}$, and Fa Jui Tan ${ }^{1, *}$
}

\author{
* Corresponding Author: Fa Jui Tan \\ Tel: +886-4-22870613 (246), \\ Fax: +886-4-22860265 \\ E-mail: tanfj@dragon.nchu.edu.tw
}

'Department of Animal Science, National Chung Hsing

University, Taichung 402, Taiwan

${ }^{2}$ Graduate Institute of Veterinary Pathobiology,

National Chung Hsing University, Taichung 402,

Taiwan

Submitted Jun 9, 2016; Revised Oct 20, 2016; Accepted Dec 5, 2016
Objective: Stripe marks, which occasionally occur on the shell, do not cause breakage to the shell and shell membranes of eggs. This study investigated the quality of intact eggs (IEs), minor stripe-marked eggs (MEs), severe stripe-marked eggs (SEs), and cracked eggs (CEs) during 3-week storage at $25^{\circ} \mathrm{C}$.

Methods: Shell eggs were collected the day after being laid and were washed. Among them, eggs without any visual cracks or stripe marks on the shells were evaluated as IEs by the plant employees using candling in a darkened egg storage room; the remaining eggs exhibited some eggshell defects. At day 3, the eggs were further categorized into IEs, MEs, SEs, CEs, and broken eggs (BEs) on the basis of the description given. Except BEs, which were discarded, the remaining eggs were stored at $25^{\circ} \mathrm{C}$ (approximate relative humidity 50\%) and then analyzed.

Results: Stripe marks were observed primarily within the first 3 days after washing. At day 3 , CEs had significantly $(\mathrm{p}<0.05)$ lower Haugh unit values, but all eggs had grades AA or A, according to the United States Department of Agriculture standard. As storage time increased, differences in egg quality between groups were more obvious. IEs had the highest eggshell breaking strength. During storage, the total plate counts and pathogens, namely Escherichia coli, Campylobacter spp., Staphylococcus aureus, and Salmonella spp., were not detectable in the internal content of IEs and SEs.

Conclusion: In conclusion, cracks degraded egg quality severely and minor stripe marks only slightly influenced the egg quality.

Keywords: Cracked Egg; Egg Quality; Haugh Unit; Microbial Quality; Storage

\section{INTRODUCTION}

Shell eggs can be considered as an inexpensive and excellent protein source accepted worldwide [1]. Egg quality considerably influences consumer acceptance and serves as a major price-determining factor for table eggs [2]. Egg quality defects reduce the quality grade, product shelf life, consumer acceptance, and hatchability of chicks, as well as increase egg breakage and packaging costs [3]. A poultry egg consists of a shell, albumen, and yolk. Egg quality defects are commonly of two types: internal and external. Internal quality defects, such as yolk mottling, yolk and albumen discoloration, rotting, a watery albumen, and the presence of blood and meat spots, occur in the yolk and albumen, and external quality defects are determined by the shape, cleanliness, integrity, texture, and soundness of shells [4]. Kingori [3] indicated that approximately $10 \%$ and $1 \%$ of total eggs produced are downgraded because of external and internal defects, respectively.

As a multifunctional biomineral complex composed of highly structured calcium carbonate, proteins, and lipids and covered with a cuticle, the eggshell functions as a barrier against microbial invasion and provides mechanical strength [5]. When observed by naked eyes, the eggshell should appear as a homogeneous structure and should be clean, smooth, and free of cracks [3]. Structural integrity of the eggshell is the minimum requirement of shell eggs. However, dam- 
ages to the eggshell at various levels might occur occasionally including washing, transportation, and storage. Some shell defects, including the occurrence of abnormalities, such as gross cracks, hairline cracks, star cracks, pimples, pinholes, a sandpaper and leathery appearance, and deformity, account for approximately $0.5 \%$ to $6 \%$ of total egg production [3]. Hamilton [6] reported that approximately $7 \%$ to $8 \%$ of the total eggs laid were discarded because of eggshell breakage. Eggshell breakages are commonly classified as a complete breakage, in which both the shell and shell membranes are damaged, or as a microcrack (hairline crack), in which the shell is broken, but shell membranes are undamaged $[7,8]$. Cracked eggs (CEs) are extremely prone to bacterial contamination; thus, cracking reduces egg quality and threatens consumer health [9]. Barnett et al [7] reported significantly $(\mathrm{p}<0.05)$ decreased hatchability of hairlineCEs, which was probably caused by increased bacterial exposure and moisture loss during incubation.

The economic value of CEs is diminished; moreover, broken eggs should be discarded undoubtedly. At present, microcracked eggs are not removed from the table egg market and incubation processes because of economic concerns or difficulties in diagnosis [7]. Some visible gray stripe marks, but not cracks, are occasionally observed on the shells of commercially washed eggs. For these eggs, no visible damages occur to the eggshell and membrane and no egg components leak out. These stripe marks are not easily visible immediately after washing, but often appear approximately 2 or 3 days later, and the eggs might have been delivered to retailers and markets. De Ketelaere et al [10] indicated that false rejection of undamaged eggs, but with little spots, scratches, or calcium deposits on the eggshell, results in a substantial financial loss. Thus, concerns about the quality of these stripe-marked eggs are increasing. In addition, whether the quality of these stripe-marked eggs is actually different from that of CEs remains unknown. Therefore, the objective of this study was to compare the internal and external qualities of stripe-marked eggs with those of intact and CEs.

\section{MATERIALS AND METHODS}

Egg sources and sampling

Shell eggs were collected the day after being laid and were washed and delivered to the lab. In total, 480 commercially washed eggs were obtained from a local processing plant (Changhua, Taiwan). Among them, 240 eggs without any visual cracks or stripe marks on the shells were evaluated as intact eggs (IEs) by the plant employees using candling in a darkened egg storage room; the remaining 240 eggs exhibited some eggshell defects. At day 3 , the eggs were further categorized into IEs, minor stripe-marked eggs (MEs), severe stripe-marked eggs (SEs), CEs, and broken eggs (BEs) on the basis of the description given in Table 1. Representative images of each type of eggs are shown in Figure 1. Except BEs, which were discarded, the remaining eggs were stored at $25^{\circ} \mathrm{C}$ (approximate relative humidity 50\%) and then analyzed.

\section{Egg quality measurement}

Egg quality was determined according to the methods proposed by $[11,12]$. Air cell size was determined using a tripod micrometer. After weighing, the eggs were manually shelled and carefully placed on the flat surface of an egg quality measurement stand (NFN-381, FHK Fujihira Industry Co., Ltd, Tokyo, Japan). The heights of the thick albumen and egg yolk were measured using an egg quality gauge (FHK NFR3, Ozaki Manufacturing, Japan), and the Haugh unit (HU) was calculated using the formula $100 \log \left(\mathrm{h}-1.7 \mathrm{w}^{0.37}+7.6\right)$, where $\mathrm{h}$ is the height of the albumen $(\mathrm{mm})$ and $\mathrm{w}$ is the weight of the egg $(\mathrm{g})$. The yolk index (YI) was calculated by measuring the width and height of the yolk by using the same micrometer as follows: YI = (yolk height)/(yolk width). After pouring the albumen through a 2-mm mesh nylon sieve, the volumes of the filtrate (thin albumen) and the residue (thick albumen) were recorded to calculate the thick albumen ratio by using the formula (thick albumen volume)/(thin albumen volume) [13]. The moisture contents of albumen and yolk were determined according to the method of Association of Analytical Communities method [14]. The $\mathrm{pH}$ values of the homogenized (BagMixer, InterScience, St. Nom., France; for 30 s) albumen and yolk of five eggs per treatment were measured using a $\mathrm{pH}$ meter (PHM 210 Standard, Radiometer, Tacussel, France) which had been calibrated previously using buffer solutions at $\mathrm{pH} 7$ and 10 , and reported as the average of the measurements.

\section{Eggshell quality measurement}

Eggshell thickness and breaking strength were determined ac-

Table 1. Description of various types of eggs analyzed

\begin{tabular}{lll}
\hline Code & Category & \multicolumn{1}{c}{ Description } \\
\hline IE & Intact egg & An egg that does not have any visual crack or gray stripe mark. \\
ME & Minor stripe-marked egg & $\begin{array}{l}\text { An egg that has a gray stripe-mark }(<2 \mathrm{~cm}) \text {, but no damage has occurred to the eggshell membrane and no egg components } \\
\text { have leaked from the egg. }\end{array}$ \\
SE & Severe stripe-marked egg & $\begin{array}{l}\text { An egg that has a single gray stripe mark or for which the sum of the lengths of individual stripe marks is more than } 2 \mathrm{~cm} \text {, but no } \\
\text { damage has occurred to the eggshell membrane and no egg components have leaked from the egg. } \\
\text { An egg that has at least one visible hair-like microcrack on the eggshell, but no damage has occurred to the eggshell membrane } \\
\text { and no egg components have leaked from the egg. } \\
\text { An egg that has at least one complete eggshell crack or hole, where the eggshell and shell membrane have broken and egg com- } \\
\text { ponents have leaked from the egg. }\end{array}$ \\
BE & Cracked egg & Broken egg
\end{tabular}


(a)

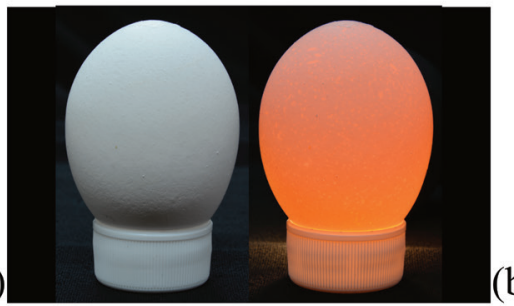

(c)

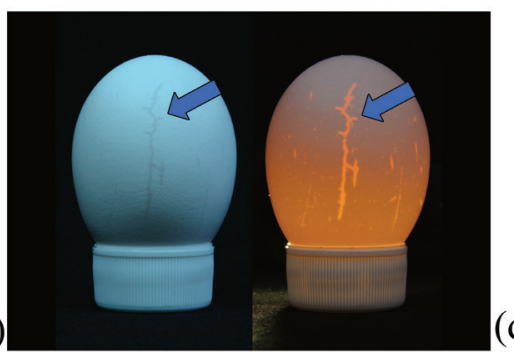

(e)

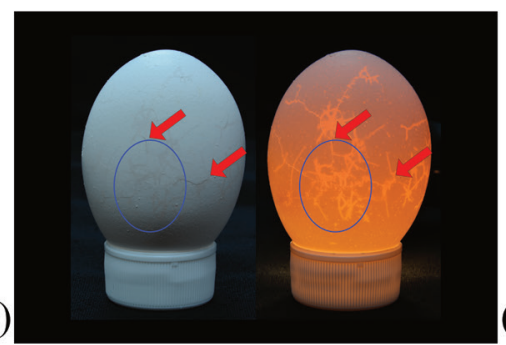

(b)

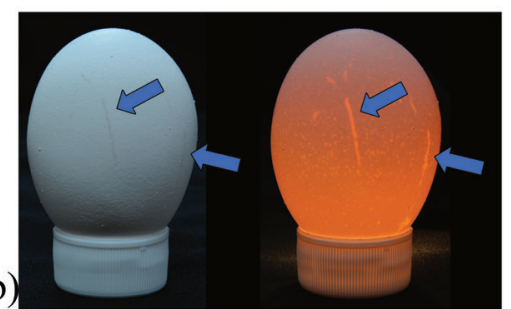

(d)

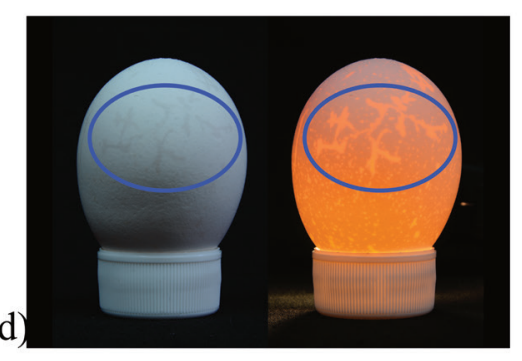

(f)

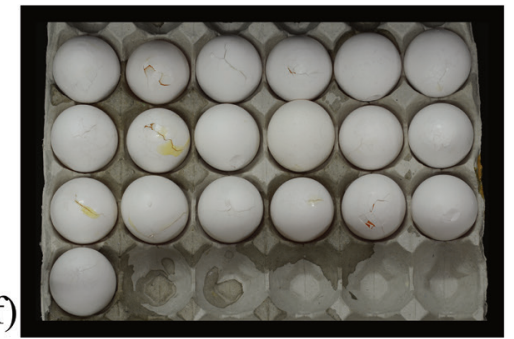

Figure 1. Different categories of eggs based on quality of egg shell; (a) intact eggs (IEs), (b) minor stripe-marked eggs (MEs), (c) severe strip-marked eggs (SEs), (d) severe stripmarked eggs (SEs), (e) cracked eggs (CEs), and (f) broken eggs (BEs). Blue arrows or circles illustrate stripe-marks; red arrows illustrate cracks.

cording to the methods of [15]. Eggshell strength was measured using an eggshell force gauge (HT-8116, Hung-Ta Instrument Co. Ltd., Taichung, Taiwan). After breaking the eggs; removing the albumen, yolk, and shell membrane; and rinsing the shell in tap water and drying it, the eggshell thickness at three points, the equator, blunt end, and sharp end, was measured using an eggshell thickness gauge (FHK FN-595, Ozaki Manufacturing, Japan) and the values were averaged.

\section{Microbiological analysis}

Microbiological analysis was conducted according to the methods of $[16,17]$. Briefly, the yolk and albumen were homogenized using a stomacher (BagMixer, InterScience, France) in a 1:10 dilution of $0.1 \%$ buffered peptone water (Difco, Sparks, MD, USA) for 1 $\mathrm{min}$. For the total plate count (TPC), viable cells (log cfu/g of egg) were enumerated on plate count agar by using the pour plate method, followed by incubation at $35^{\circ} \mathrm{C}$ for $48 \mathrm{~h}$. Escherichia coli (E. coli) was enumerated on MacConkey agar and incubated aerobically at $37^{\circ} \mathrm{C}$ for $16 \mathrm{~h}$. Campylobacter spp. were enumerated on charcoal cefoperazone deoxycholate agar and incubated at $42^{\circ} \mathrm{C}$ for 24 h. Staphylococcus aureus (S. aureus) was enumerated on Baird-Parker agar and incubated at $37^{\circ} \mathrm{C}$ for $24 \mathrm{~h}$. For Salmonella spp. detection, sample homogenates were enriched using tetrathionate broth and incubated at $35^{\circ} \mathrm{C}$ for $24 \mathrm{~h}$ before being plated on xylose lysine tergitol 4 agar at $35^{\circ} \mathrm{C}$ for $24 \mathrm{~h}$ before detection.

\section{Visual observation of eggshells}

Using an egg candler (Hong Fu, New Taipei City, Taiwan) as a light source, a camera (D5200, Nikon, Tokyo, Japan) set to the complete manual mode, an aperture of $f / 13$, and a shutter speed of $2.5 \mathrm{~s}$ were used to capture the images of eggs at the same position every 3 days.

\section{Statistical analysis}

The means of the data were compared using the one-way analysis of variance with a $5 \%$ level of significance. The means were separated using the Scheffé test. All statistical analyses were performed using Statistical Analysis System [18].

\section{RESULTS AND DISCUSSION}

\section{Albumen quality}

Figure 2 shows the albumen quality of eggs visually categorized by the occurrence of cracks or stripe marks during 3-week storage at $25^{\circ} \mathrm{C}$. Egg quality was evaluated on the basis of the United States Department of Agriculture (USDA) standard: eggs with $\mathrm{HU}$ values of $>72,71$ to 60,59 to 31 , and $<31$ were classified into grades AA, A, B, and C, respectively [19]. The results indicated that the $\mathrm{HU}$ values decreased gradually with storage time, indi- 
(a)

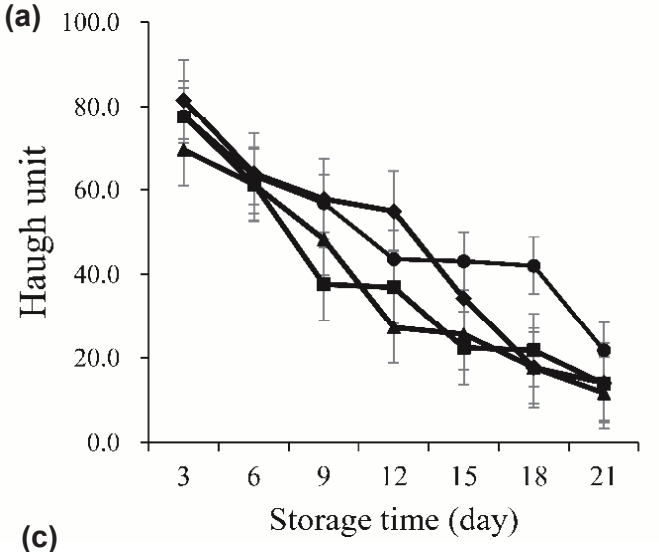

(c)

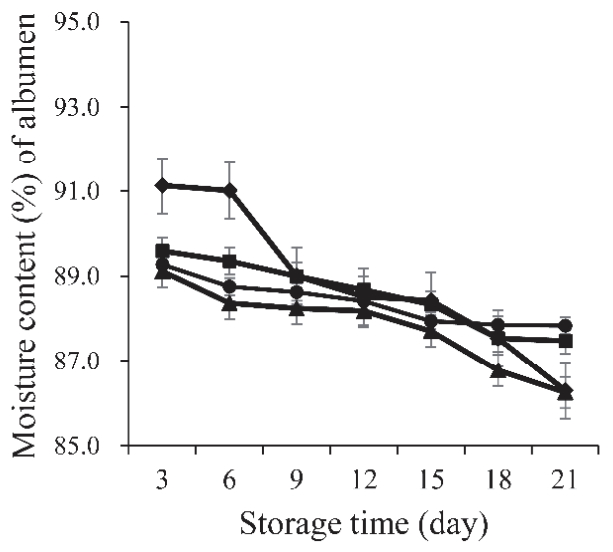

(b)

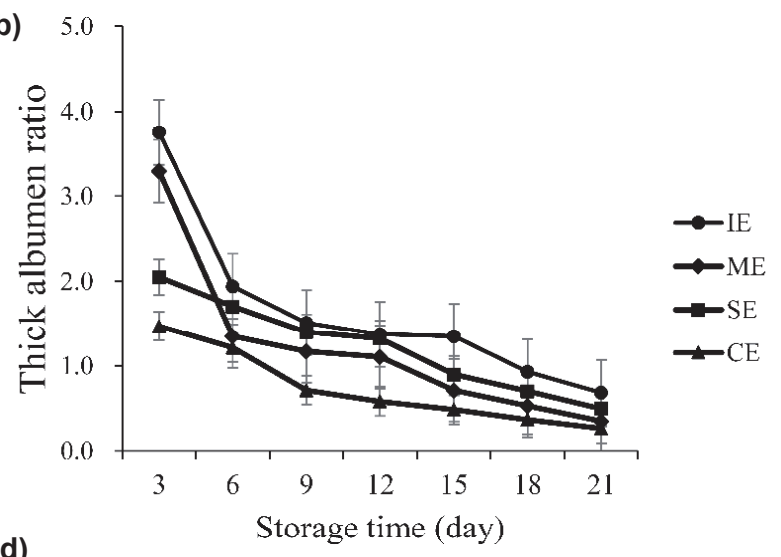

(d)

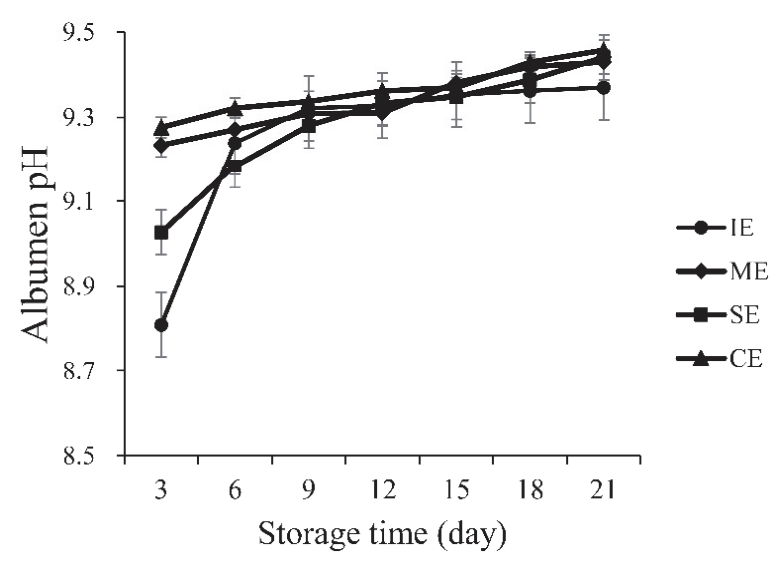

Figure 2. Changes in (a) Haugh unit, (b) thick albumen ratio, (c) moisture content (\%) of albumen, and (d) albumen pH of different categories of eggs during storage. IE, intact egg; $\mathrm{ME}$, minor stripe-marked egg; SE, severe stripe-marked egg; CE, cracked egg.

cating that egg quality deteriorated as expected [11]. At day 3, the HU value for CEs was significantly $(\mathrm{p}<0.05)$ lower than those for IEs, MEs, and SEs (69.4 vs 77.5 to 81.6; Figure 2a). According to the USDA standard, grade AA for IEs, MEs, and SEs and grade $\mathrm{A}$ for $\mathrm{CEs}$ indicate excellent quality at day 3 . After storage for 15 days at $25^{\circ} \mathrm{C}$, IEs exhibited significantly $(\mathrm{p}<0.05)$ higher $\mathrm{HU}$ values than those of the other eggs, of which the $\mathrm{HU}$ values decreased in the order MEs, SEs, and CEs. At day 12, the HU value of CEs decreased to grade $\mathrm{C}$, which is the criterion indicating that eggs should not be eaten. As the storage time increased, particularly after storage for more than 18 days, MEs, SEs, and CEs had significantly $(\mathrm{p}<0.05)$ lower HU values than IEs did. At day 18, the grade B of IEs demonstrated acceptable quality, whereas the grade $\mathrm{C}$ of MEs, SEs, and CEs demonstrated unacceptable quality. In the current study, it took $21,18,15$, and 12 days, respectively, for the HU values of IEs, MEs, SEs, and CEs to decline to grade $C$.

Similar decreasing patterns during storage were also observed in the thick albumen ratio and moisture content of egg albumen. At day 3, IEs and MEs had significantly $(\mathrm{p}<0.05)$ higher thick albumen ratios than SEs and CEs did $(\mathrm{p}<0.05)$. During storage, IEs exhibited the highest thick albumen ratio, followed by MEs, SEs, and CEs; CEs tended to possess a low albumen moisture content. Figure $2 \mathrm{~d}$ shows that at day 3 , IEs had a significantly $(\mathrm{p}<0.05)$ lower albumen $\mathrm{pH}$ than MEs, SEs, and CEs $\operatorname{did}(\mathrm{p}<0.05)$. During storage, the albumen $\mathrm{pH}$ increased probably because the release of carbon dioxide modified the carbonic acid-bicarbonate buffer system in the albumen [11,13]. Storage temperature and duration substantially influenced the $\mathrm{HU}$, height, and $\mathrm{pH}$ of the albumen, and weight loss of the egg [11].

\section{Yolk quality and air cell size}

The YI, the ratio of the yolk height to diameter, is frequently used as an index of egg quality [13]. Figure 3 shows that the YI values decreased but the yolk $\mathrm{pH}$ increased with storage time. A freshly laid egg, which has a firm round yolk and a strong yolk membrane, has a higher YI than that of an older egg [17]. During extended storage, particularly at high temperature, yolk flattening because of osmotic migration from the albumen through the weaker vitelline membrane reduces the YI [13]. Figure $3 \mathrm{~d}$ shows that the air cell size increased with storage time [11]. Some physicochemical changes occur during egg storage. For example, moisture and carbon dioxide are lost through the eggshell, and thus, the moisture content decreases and the $\mathrm{pH}$ of the albumen and yolk and the air cell size increase [11]. During extended storage, the ovomucin-lysozyme complex destabilized by protease 


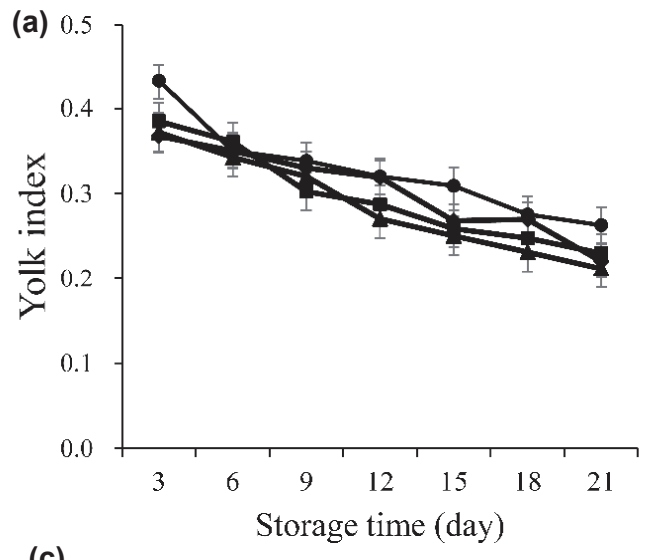

(c)

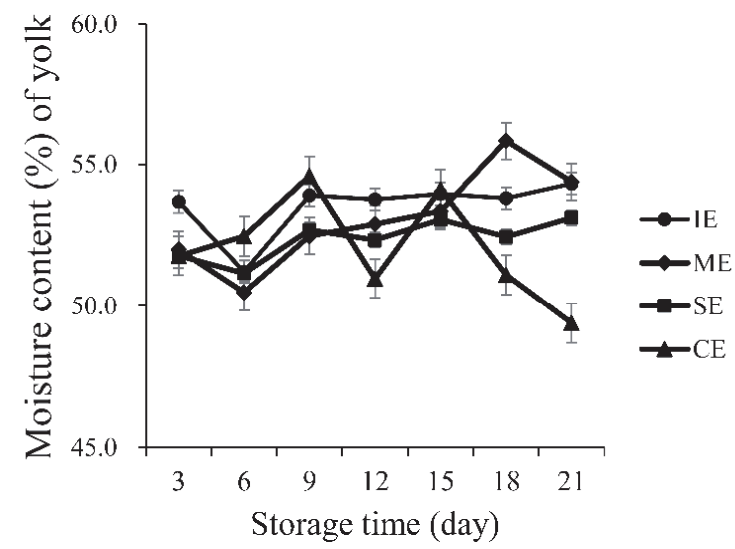

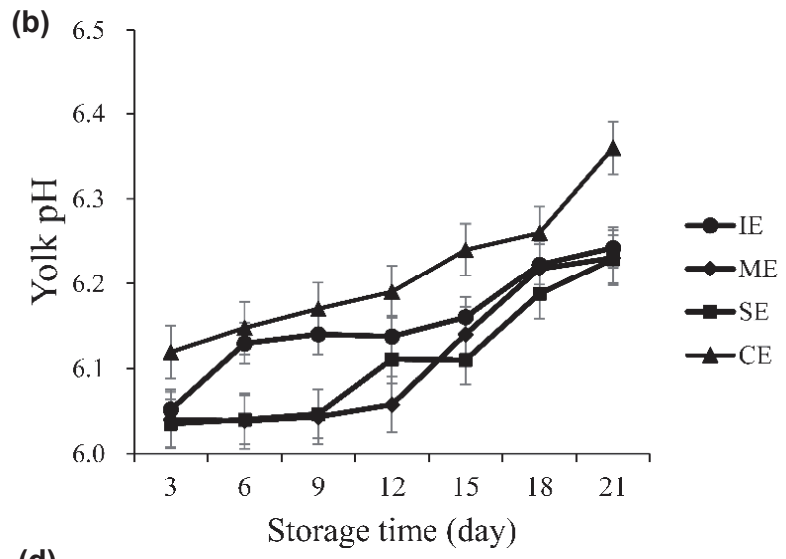

(d)

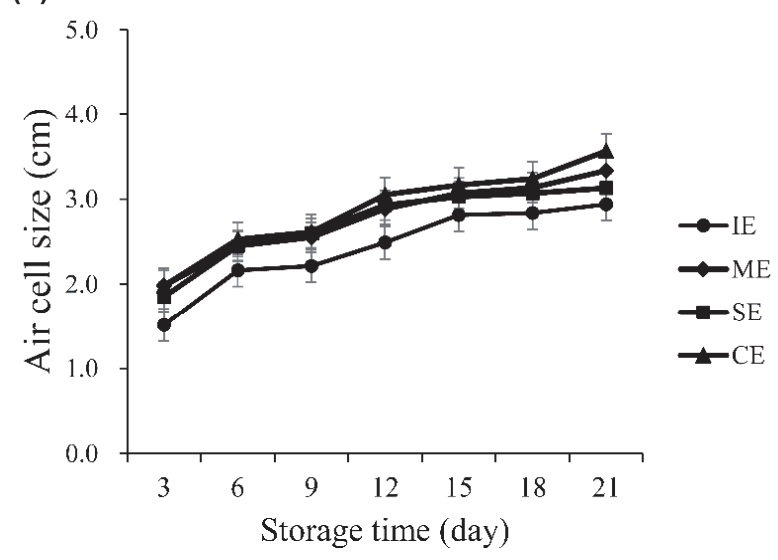

Figure 3. Changes in (a) yolk index, (b) yolk pH, (c) moisture content (\%) of yolk, and (d) air cell size of different categories of eggs during storage. IE, intact egg; ME, minor stripemarked egg; $S E$, severe stripe-marked egg; $C E$, cracked egg.

enzymes deteriorates the gelatinous structure of thick albumen as the $\mathrm{pH}$ increases, and eventually resulting in albumen liquefaction $[1,13]$. Meanwhile, yolk flattening occurs probably because of osmotic migration of water from the albumen through the weaker vitelline membrane. Many parameters, including the HU, $\mathrm{pH}$ of the albumen and yolk, and air cell size, which are influenced considerably by storage duration and temperature, have been recommended as quality indices for evaluating the freshness of eggs [11]. During storage, IEs had significantly $(p<0.05)$ smaller air cells than MEs, SEs, and CEs. The results suggest that the greater the integrity of the eggshell structure, the less the loss of water and carbon dioxide through the eggshell is, thus leading to a smaller increase in the air cell size as well as higher internal egg quality.

\section{Eggshell quality}

CEs had thinner eggshells (Figure 4a), whereas IEs had the highest eggshell breaking strength, followed by MEs and SEs, and CEs (Figure $4 \mathrm{~b}$ ). Eggs with lower eggshell quality, specifically those with thinner eggshells and lower breaking strength, probably develop more cracks. Because of the loss of protection from the eggshell, the internal quality of eggs with more cracks on the shells degrades more rapidly. Samli et al [11] reported that storage duration and temperature significantly influenced egg quality. Similarly, Monira et al [20] indicated that breed and storage duration substantially influenced eggshell and internal egg quality. Samli et al [11] ascribed most changes in egg quality, including those in the HU, YI, albumen height and $\mathrm{pH}$, and air cell size, to the release of carbon dioxide from the albumen and water evaporation through the pores in the shell. Therefore, more moisture loss from thin-shelled eggs probably resulted in more quality deterioration for table eggs [3]. Poultry eggs serve as food for humans as well as the organic medium for the reproduction of birds [2]. Studies have shown that thin-shelled eggs lose more moisture during incubation, thus influencing hatchability [3]. Higher microbial exposure and increased water loss resulted in an approximately 25\% reduction in the hatchability of CEs [7]. Chukwuka et al [2] listed many factors, such as nutrition, the age and genetic composition of hens, diseases, and ingestion of some sulfa drugs, influencing eggshell quality. Kingori [3] intensively reviewed some potential causes of decreased eggshell thickness. For example, stress, such as that caused by staying at a high ambient temperature and in a high humidity environment, impairs feed and calcium intake, inhibits calcium carbonate formation in the shell gland, and consequently reduces eggshell thickness. 
(a)

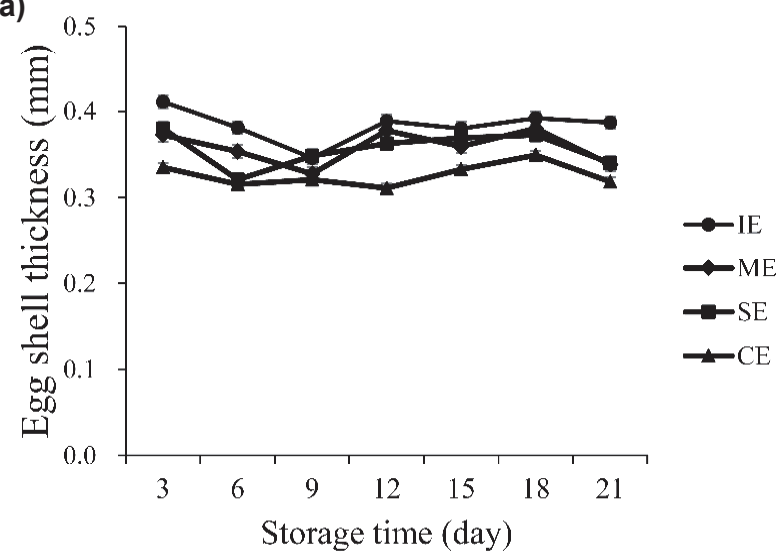

(b)

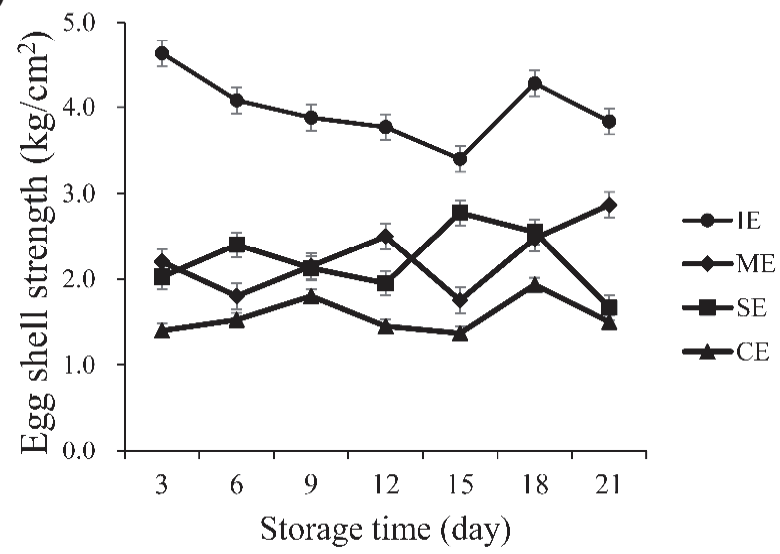

Figure 4. Changes in (a) eggshell thickness and (b) eggshell breaking strength of different categories of eggs during storage. IE, intact egg; ME, minor stripe-marked egg; SE, severe stripe-marked egg; CE, cracked egg.

During storage, the results show that the TPC and all pathogens, including E. coli, Campylobacter spp., S. aureus, and Salmonella spp., of eggs were not detectable for the internal contents of IEs and SEs (data not shown). Because bacteria might readily penetrate the eggshell and membrane of an egg, CEs are prone to bacterial contamination and quality degradation, and thus, cracking endangers consumer health [21]. Barnettet al [7] observed that hairline-cracked broiler breeder eggs had increased bacterial exposure. More eggshell penetration of Salmonella spp. was observed for eggs having lower eggshell strength and lacking cuticle spots. The TPC is a microbial quality indicator of samples and is commonly used in the food industry. According to Ricke et al [22] and Theron et al [23], egg and egg products should meet the requirements of a TPC less than $2.5 \times 10^{4} \mathrm{cfu} / \mathrm{g}$ and the absence of Salmonella spp. and S. aureus. The eggshell, assisted by shell membranes and cuticle layers, physically prevents bacterial invasion and microbial contamination [24]. Some cuticle proteins, such as lysozyme $\mathrm{C}$, ovotransferrin, ovocalyxin-32, and ovocleidin-17, enhance eggshell defense against bacterial contamination and maintain egg quality [25]. Our results indicated that IEs and SEs were microbiologically safe throughout the storage period. The presence of stripe marks on the eggshell did not influence the microbial quality of eggs, particularly the microorganisms tested in the current study.

\section{Visual observation}

At day 3, additional stripe marks (approximately 11\%) were observed on the shells of IE eggs; however, no more new stripe marks were observed from day 4 onwards. Small cracks cannot be easily detected, and sometimes, they can be detected only after a few days of storage [26]. The exhibited cracks and stripe marks on the eggshells did not change between day 4 and the end of storage (Figure 5). Some cracks appeared on the SEs. However, according to visual observation, the progress of the stripe marks and cracks was not related. In other words, cracks did not develop into stripe marks, and vice versa. However, such subjective observation by naked eye must be confirmed through other methodologies, such as imaging analysis [27] and acoustic resonance frequency analysis [10], in the future.

Although eggshell cracks have been extensively evaluated, there is no clear definition regarding eggshell defects. For example, Khabisi et al [8] included major eggshell damages as complete eggshell breakage, hairline cracks, and star cracks. Arivazhagan et al [28] defined gross cracks as large cracks and holes that result in a broken shell membrane, whereas hairline cracks and star cracks are extremely fine cracks usually running lengthwise along the shell and slightly indented cracks radiating outward from a central point of impact, respectively. Moreover, Kingori [3] commented that the complexity of the eggshell structure leads to different breakages, such as cracks of various severities, shapes, and lengths, in eggs.

\section{CONCLUSION}

We demonstrated that the presence of stripe marks on the eggshell did not reduce the microbial quality of eggs. Cracks degraded the egg quality more severely than other defects did, whereas minor stripe marks slightly influenced egg quality. Higher eggshell quality is probably attributed to the enhanced internal quality of IEs. Because no single factor, such as genetics, health, nutrition, husbandry management, and environmental conditions, is solely responsible for egg quality defects, recognizing the various causes of egg defects is necessary to minimize and, therefore, improve egg quality. What cause strip marks remains unclear yet even though it might be related to washing. More efforts should be addressed to understand and prevent, or at least reduce, the possible causes of the occurrence of stripe marks. Additional analytical techniques are required to distinguish cracks and stripe marks. 
(a)

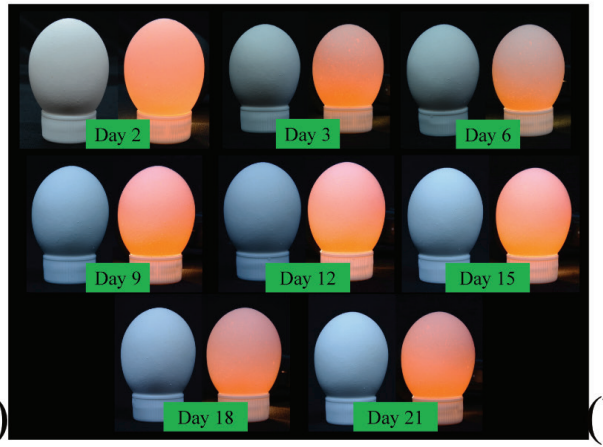

(b)

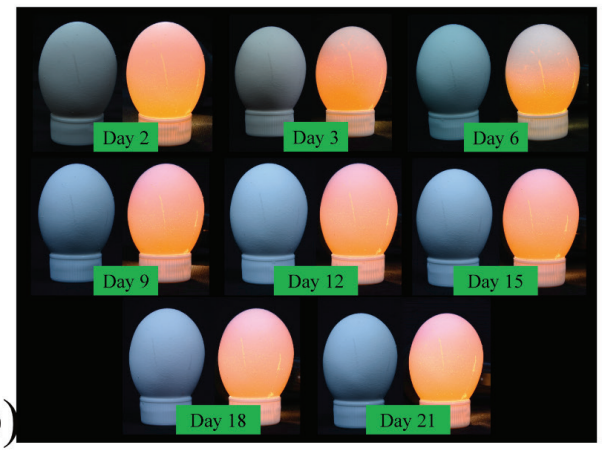

(c)
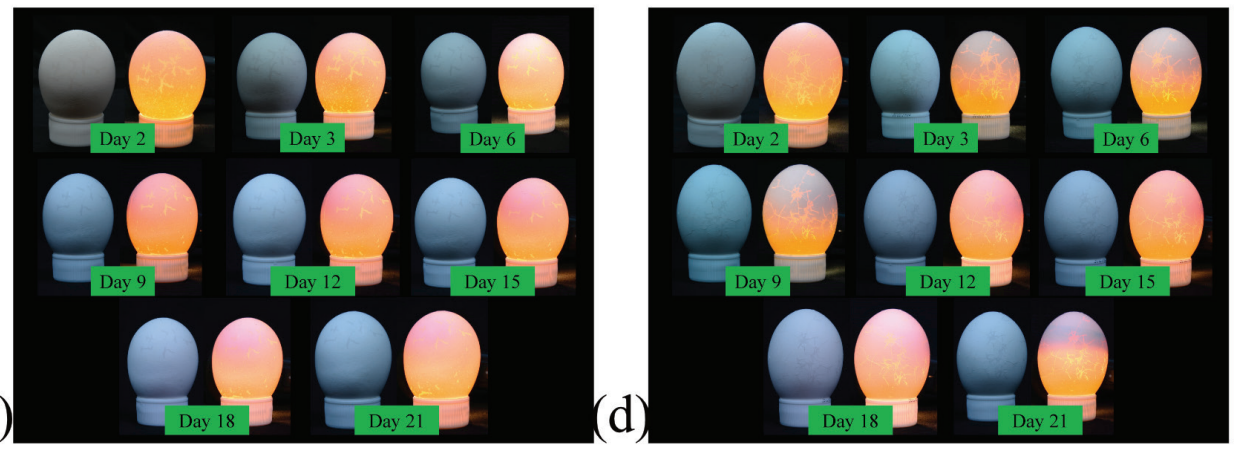

Figure 5. Appearance observation of (a) IE, (b) ME, (c) SE, and (d) CE eggs during storage. IE, intact egg; ME, minor stripe-marked egg; $S E$, severe stripe-marked egg; CE, cracked egg.

\section{CONFLICT OF INTEREST}

We certify that there is no conflict of interest with any financial organization regarding the material discussed in the manuscript.

\section{ACKNOWLEDGMENTS}

This work was financially supported by the Council of Agriculture, Taiwan (103AS-14.2.3-AD-U1).

\section{REFERENCES}

1.Yuceer M, Caner C. Antimicrobial lysozyme-chitosan coatings affect functional properties and shelf life of chicken eggs during storage. J Sci Food Agr 2014;94:153-62.

2.Chukwuka OK, Okoli IC, Okeudo NJ, et al. Egg quality defects in poultry management and food safety. Asian J Agric Res 2011;5:1-16.

3.Kingori AM. Egg quality deffects: Types, causes and occurrence: a review. J Anim Prod Adv 2012;2:350-7.

4.Roberts JR. Factors affecting egg internal quality and egg shell quality in laying hens. J Poult Sci 2004;41:161-77.

5.Wellman-Labadie O, Picman J, Hincke MT. Antimicrobial activity of the Anseriform outer eggshell and cuticle. Comp Biochem Physiol B: Biochem Mol Biol 2008;149:640-9.

6.Hamilton RMG. Methods and factors that affect the measurement of egg shell quality. Poult Sci 1982;61:2022-39.
7.Barnett DM, Kumpula BL, Petryk RL, Robinson NA. Hatchability and early chick growth potential of broiler breeder eggs with hairline cracks. J Appl Poult Res 2004;13:65-70.

8.Khabisi MM, Salahi A, Mousavi SN. The influence of egg shell crack types on hatchability and chick quality. Turk J Vet Anim Sci 2012;36: 289-95.

9.Todd ECD. Risk assessment of use of cracked eggs in Canada. Int J Food Microbiol 1996;30:125-43.

10. De Ketelaere B, Coucke P, De Baerdemaeker J. Eggshell crack detection based on acoustic resonance frequency analysis. J Agr Eng Res 2000; 76:157-63.

11. Samli HE, Agma A, Senkoylu N. Effects of storage time and temperature on egg quality in old laying hens. J Appl Poult Res 2005;14: 548-53.

12. Huang Q, Qiu N, Ma MH, et al. Estimation of egg freshness using S-ovalbumin as an indicator. Poult Sci 2012;91:739-43.

13. Ragni L, Al-Shami A, Mikhaylenko G, Tang J. Dielectric characterization of hen eggs during storage. J Food Eng 2007;82:450-9.

14. AOAC International. Official methods of analysis of AOAC International. 15th ed. Association of Official Analytical Chemists: Arlington VA: AOAC International; 1990.

15. Sun CJ, Chen SR, Xu GY, Liu XM, Yang N. Global variation and uniformity of eggshell thickness for chicken eggs. Poult Sci 2012;91: 2718-21.

16. Torrico DD, No HK, Prinyawiwatkul W, et al. Mineral oil-chitosan emulsion coatings affect quality and shelf-life of coated eggs during 
refrigerated and room temperature storage. J Food Sci 2011;76:S262-8.

17. Cader S, Goburdhun D, Neetoo H. Assessment of the microbial safety and quality of eggs from small and large-scale hen breeders. J World's Poult Res 2014;4:75-81.

18. Statistical Analysis System (SAS) Institute Inc. Version 9.4. Cary, NC: SAS Institute Inc.; 2014.

19. USDA. U.S. Department of Agriculture. United States standards, grades, and weight classes for shell eggs. AMS 56.210. AMS. Washington, DC: USA; 2000.

20. Monira KN, Salahuddin M, Miah G. Effect of breed and holding period on egg quality characteristics of chicken. Int J Poult Sci 2003;2:261-3.

21. Messens W, Grijspeerdt K, Herman L. Eggshell penetration by Salmonella: a review. Worlds Poult Sci J 2005;61:71-86.

22. Ricke SC, Birkhold SG, Gast RK. Eggs and egg products. In: Downes FP, Ito K, editors. Compendium of methods for the microbiological examination of foods. Washington, DC: American Public Health Association; 2001.p. 473-81.
23. Theron H, Venter P, Lues JFR. Bacterial growth on chicken eggs in various storage environments. Food Res Int 2003;36:969-75.

24. De Reu K, Grijspeerdt K, Messens W, et al. Eggshell factors influencing eggshell penetration and whole egg contamination by different bacteria, including Salmonella enteritidis. Int J Food Microbiol 2006;112: 253-60.

25. Rose-Martel M, Du J, Hincke MT. Proteomic analysis provides new insight into the chicken eggshell cuticle. J Proteomics 2012;75:2697706.

26. Wang J, Jiang R. Eggshell crack detection by dynamic frequency analysis. Eur Food Res Technol 2005;221:214-20.

27. Lawrence KC, Yoon SC, Heitschmidt GW, Jones DR, Park B. Imaging system with modified-pressure chamber for crack detection in shell eggs. Sens Instrum Food Qual Saf 2008;2:116-22.

28. Arivazhagan S, Shebiah RN, Sudharsan H, Kannan RR, Ramesh R. External and internal defect detection of egg using machine vision. J Emerg Trends Comput Inform Sci 2013;4:257-62. 